\title{
Chefarzt und Mitarbeiter
}

Richard O. Binswanger

\footnotetext{
* Aus stilistischen Gründen wird die männliche Form verwendet. Chefärztinnen und Mitarbeiterinnen sind ausdrücklich mitgemeint.
}

Korrespondenz:

Dr. med. Richard O. Binswanger Radiologie und

Nuklearmedizin FMH

Führungsschule Bodensee Münsterlingen

Oberer Seeweg 9

CH-8597 Landschlacht

r.binswanger@bluewin.ch

fsb-spital.ch

\section{Rechte und Pflichten}

Als Chefarzt* sind Sie in der Pflicht. Ihre Mitarbeiter ebenfalls. Vom letzteren wird wenig gesprochen, meistens geht es um die Rechte der Mitarbeitenden. Dazu gehören alle personalrechtlichen Bestimmungen, das Recht auf Information, auf Achtung der Persönlichkeit und der Privatsphäre, auf Förderung und vieles mehr. Hier soll aber von den Pflichten der Mitarbeiter gesprochen werden, worüber oft $\mathrm{zu}$ wenig nachgedacht und kommuniziert wird (Damit ist ausdrücklich nicht das Pflichtenheft gemeint!). Denn das Bewusstsein über die eigenen Pflichten wird vielfach einfach vorausgesetzt, obwohl nicht von vorneherein klar ist, dass alle diese kennen und danach handeln.

\section{Präsenz und Zusammenarbeit}

Mitarbeiter sollen in ihrer Dienstzeit nicht nur anwesend sein, sondern auch in jeder Hinsicht präsent. Sie sollen ihr Privatleben samt den dazugehörigen Problemen oder Störfaktoren zu Hause lassen und sich auf ihre Aufgabe konzentrieren. Vor allem sollen sie andere nicht mit Problemen belästigen. Das entbindet den Chef allerdings nicht davon, einfühlend nachzufragen, wenn jemand traurig oder verstimmt ist. Jeder Mitarbeiter soll mit jedem anderen zusammenarbeiten können, unabhängig von Sympathie oder Antipathie. Diese Forderung soll qualifizierend sein. Nachdem dies in unserer Klinik einmal klargestellt war, nahmen Konflikte dramatisch ab.

\section{Interessen des Betriebs und Kommunikation}

Mitarbeiter sollen die Interessen des Betriebs wahrnehmen und sich dafür einsetzen. Dazu gehört auch, dass man Aussenstehenden kein negatives Bild seines Arbeitsplatzes vermittelt. Wer klagt, stellt auch sich selbst negativ dar. Mitarbeiter sollen höflich und korrekt kommunizieren. Manchmal hilft eine Schulung dazu weiter. Vor allem der Umgang mit Patienten und anderen Abteilungen des Spitals soll einwandfrei sein. Das ist nicht immer einfach, vor allem wenn man angegriffen wird. Dann soll man den Angreifer möglichst geschickt «herunterholen», im Bewusstsein der Tatsache, dass dieser ja seine eigenen Probleme zu bewältigen hat und gestresst oder gar in Not sein kann. Eine gute Kommunikation entschärft alle Konflikte.

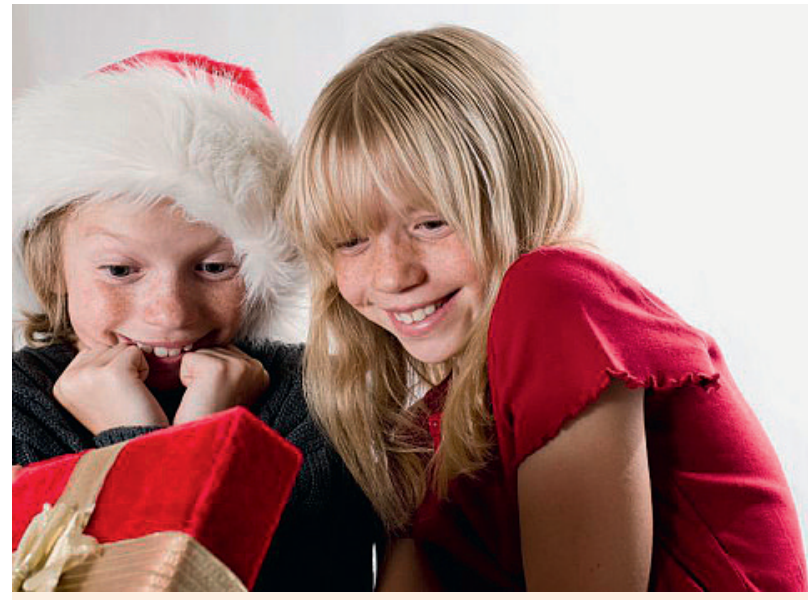

Überraschungen sind bei Chefärzten meist weniger beliebt als bei diesen beiden.

\section{Kritik und Eigenverantwortung}

Mitarbeiter sollen kritisch sein und ihre Kritik auch anbringen. Das ist, Vorgesetzten gegenüber, gar nicht so einfach. So kommt Kritik oft verklausuliert oder unterschwellig daher. Deshalb braucht es viel Gespür vonseiten der Leitenden, um diese Botschaften auch aufzunehmen. Wenn dieses fehlt, muss sich Kritik notfalls lautstark artikulieren. Jeder Mitarbeiter ist für sein Fortkommen selbst verantwortlich. Er soll sich weiter- und fortbilden. Dies auf eigene Initiative, aber nicht ohne Unterstützung seiner Vorgesetzten. Wenn er dieser Forderung entspricht, aber trotzdem nicht vorwärts kommt, ist er bestens gerüstet für einen Stellenwechsel.

\section{Überraschung, Loyalität und Erfolg}

Mitarbeiter sollen ihren Chef nicht überraschen. Sie sollen relevante Informationen frühzeitig weitergeben. Bei Problemen im Rahmen von Aufträgen und Projekten ist dies besonders wichtig. So entstehen geschlossene Informationskreisläufe, ein wichtiges Schmiermittel für das Funktionieren der Klinik. Mitarbeiter sollen ihrem Chef gegenüber loyal sein, umgekehrt auch. Und schliesslich sollen Mitarbeiter ihrem Chef zum Erfolg verhelfen, das macht sie selbst erfolgreich. 